\title{
Glial Cells Promote Muscle Reinnervation by Responding to Activity-Dependent Postsynaptic Signals
}

\author{
Flora M. Love and Wesley J. Thompson \\ Section of Neurobiology, School of Biological Sciences, Institute for Neuroscience and Institute for Cell and Molecular \\ Biology, University of Texas at Austin, Austin, Texas 78712
}

After nerve injury, denervated synaptic sites in skeletal muscle commonly become reinnervated by sprouts that grow from nerve terminals on nearby muscle fibers. These terminal sprouts grow along a glial cell guide or "bridge" formed by Schwann cell (SC) processes that extend from denervated synaptic sites. Data presented here show that most bridges connect innervated and denervated synaptic sites rather than pairs of denervated sites even when most sites in the muscle are denervated. Furthermore, bridges are inhibited by presynaptic or postsynaptic blockade of synaptic transmission, manipulations that do not alter the extent of SC growth. These results show that an activity-dependent postsynaptic signal promotes the formation and/or maintenance of glial bridges and thus muscle reinnervation.

Key words: reinnervation; Schwann cells; glia; neuromuscular junction; activity-dependent; postsynaptic
Terminal Schwann cells (TSCs) are glial cells that sit above the neuromuscular junction and cover the nerve terminal branches with their processes. After denervation, TSCs elaborate an array of processes that extend away from the synaptic site or endplate (Reynolds and Woolf, 1992). In muscles in which only some of the axons are damaged (i.e., after "partial denervation"), the TSC processes extended from the denervated endplates grow to adjacent, innervated endplates and thus form links or bridges between the synaptic sites. These bridges then promote the growth of terminal sprouts and guide the sprouts to the denervated endplates where new nerve terminals are formed (Son and Thompson, 1995b). Recent evidence suggests that TSC bridges are necessary for the reinnervation of muscle fibers by terminal sprouts (Lubischer and Thompson, 1999).

Previous studies have assumed that bridges form randomly, as TSC processes extending from denervated endplates encounter other endplates. We have investigated this assumption by exploring circumstances under which bridges form. Because of previous reports that neuromuscular activity influences sprouting in muscles (Brown et al., 1981), we have investigated whether synaptic activity promotes the formation and/or maintenance of such bridges. Here we present evidence that bridge formation and maintenance is not random and is regulated by the activity of synaptic contacts. We consider how these results add to the extensive literature on the stimuli for nerve growth in muscle.

Parts of this paper have appeared in abstract form (Love and Thompson, 1998a).

Received Aug. 3, 1999; revised Sept. 8, 1999; accepted Sept. 10, 1999.

This work was supported by grants from the National Institutes of Health and the National Science Foundation. We thank Jane Lubischer for critical comments on this manuscript.

Correspondence should be addressed to Flora M. Love, School of Biological Sciences, University of Texas at Austin, Austin, TX 78712. E-mail: flora. love2@gte.net.

Copyright (C) 1999 Society for Neuroscience 0270-6474/99/1910390-07\$05.00/0

\section{MATERIALS AND METHODS}

Animals and surgery

Animals were anesthetized by intraperitoneal injections of ketaminexylazine before surgical procedures. At the end of the experiments, muscles were removed under deep ether anesthesia and immersed in oxygenated Ringer's solution (Liley, 1956) for tension recordings.

Partial denervation. AO rats in which innervation of the soleus is often derived from two separate nerves (Thompson and Jansen, 1977) were used. Partial denervation was accomplished by resecting the larger of these two nerves (the soleus nerve) either at the head of the gastrocnemius (in the bungarotoxin experiments and one set of botulinum toxin experiments designed to be comparable to the bungarotoxin experiments) or at its entry into the muscle (all other experiments).

Reinnervation. Ten-week-old Wistar rats in which the soleus muscle is innervated by only the soleus nerve were used. Denervation was accomplished by nerve crush $1 \mathrm{~mm}$ from the muscle. The muscles were examined 7-8 and 12 d later. Results were compared to those obtained in a separate set of animals in which the soleus was denervated by nerve resection and remained denervated for the entire $12 \mathrm{~d}$.

\section{Botulinum toxin administration}

The soleus muscle was exposed by a medial incision in the hind limb in 10-week-old rats. Immediately after partial denervation, 6-10 ng of botulinum toxin A (botox, catalog \#203674; Calbiochem, La Jolla, CA), dissolved in $12 \mu \mathrm{l}$ of $0.1 \mathrm{M}$ PBS with $0.2 \%$ gelatin (vehicle), was applied directly to the muscle surface and allowed to remain for $5 \mathrm{~min}$. The skin was sutured after removal of excess fluid. The same procedure was used for control animals except that only vehicle was applied. At the time muscles were removed, they were examined for contraction elicited by nerve stimulation. Muscles remained completely paralyzed for $3 \mathrm{~d}$ after a single application of botox. Seven days after a single application of botox, nerve-evoked muscle twitch and tetanic tensions were $2-6 \%$ of tensions elicited by direct muscle stimulation.

\section{$\alpha$-bungarotoxin administration}

Achieving a sustained block with $\alpha$-bungarotoxin (btx) was more difficult than with botox, necessitating repeated applications of btx. Therefore, a different protocol was used to minimize the period of exposure to btx to a time when bridges are forming rapidly, between 48 and $72 \mathrm{hr}$ after partial denervation. The soleus muscle was exposed by an incision in the skin on the medial side of the hind limb $48 \mathrm{hr}$ after partial denervation in 5- to 6-week-old rats (smaller animals were used to increase the likelihood of btx penetrating throughout the muscle). The soleus muscle was separated from adjacent muscles by running a fire-polished glass probe through the connective tissue on both sides of the muscle. Partially 
denervated muscles were treated with $10-12 \mu \mathrm{g}$ of btx (ABT/98A; Biotoxins), dissolved in 15-18 $\mu \mathrm{l}$ of $0.1 \mathrm{M}$ PBS/Ringer's solution with $0.2 \%$ gelatin, applied directly to the muscle surfaces and allowed to remain for $2 \mathrm{hr}$. The muscles were then rinsed with Ringer's solution before suturing the wound. Twelve hours after the initiation of the first dose, a second dose of $10-12 \mu \mathrm{g}$ was applied for $2 \mathrm{hr}$. The muscles were examined $12 \mathrm{hr}$ later, i.e., $24 \mathrm{hr}$ after initiation of block. The same procedure was used for control animals with the exception that only vehicle was applied. Preliminary experiments established the effectiveness of this procedure. When btx was applied in this manner to fully innervated muscles for $1 \mathrm{hr}$, only $1-3 \%$ of the direct tension could be elicited by nerve stimulation immediately after btx application.

\section{Evaluation of synaptic transmission}

Soleus muscles treated with botox or btx were removed and pinned through the proximal tendon to Sylgard-coated dishes, and superfused with oxygenated Ringer's solution. The distal tendon of the muscle was attached to a Harvard Apparatus isometric tension transducer (model 60-2996; sensitivity, $40 \mathrm{mV} / \mathrm{gm}$ tension). The nerve was stimulated through an attached suction electrode with stimulus pulses $0.2 \mathrm{msec}$ in duration. The output of the tension recorder was digitized using a MacLab analog-to-digital converter and analyzed using a Macintosh computer. Maximal twitch and tetanic tensions $(20,50$, and $100 \mathrm{~Hz})$ were recorded. Maximal twitch and tetanic tensions were also recorded during direct stimulation, accomplished by passing current pulses, $2 \mathrm{msec}$ in duration, between two platinum electrodes placed on either side of the muscle belly.

\section{Whole-mount immunolabeling}

The protocol described in Love and Thompson (1998b) was followed with two exceptions: (1) nerve terminals were labeled with mouse monoclonal antibodies to SV-2 (Developmental Studies Hybridoma Bank), diluted 1:500, and (2) permeabilization using methanol was omitted for muscles that were treated with btx or its vehicle because such treatment was found to reduce the intensity of subsequent fluorescent btx labeling.

\section{Analysis}

For all experiments, two to four thin layers were dissected and viewed in whole-mount from the interior of each muscle. Each layer typically had 100-200 visible endplates. Terminal sprouts were identified as neurofilament-labeled processes extending from endplates. TSC bridges were identified as S-100-labeled processes linking two endplates. In partially denervated muscles, bridges between innervated and denervated endplates were counted as a percentage of the total number of innervated endplates remaining after denervation. Those endplates reinnervated by nodal sprouts were not counted; at early times after partial denervation, nodal sprouts have several characteristics that distinguish them from normally innervated endplates, such as a thin preterminal axon and terminal processes that only partially occupy the underlying acetylcholine receptors. In addition, they can often be traced to the node from which they originate. In reinnervation experiments (i.e., those in which the nerve was crushed), bridges were counted as the number of endplates linked by a bridge out of all endplates examined (TSC processes from one endplate rarely connected more than one endplate, thus one bridge connects two endplates. Therefore, the number of endplates linked by a bridge was counted as twice the number of bridges). In each muscle, the number and length of TSC processes at denervated endplates was measured at a minimum of 25 endplates having an en face orientation.

\section{RESULTS}

\section{Schwann cell processes growing from denervated endplates preferentially bridge with innervated endplates}

In partially denervated muscles, TSCs at denervated endplates extend an array of processes that grow beyond the boundary of the endplate. Some of these processes contact other endplates, thereby forming a bridge. To determine whether these bridges form randomly, we used immunohistochemistry to examine rat soleus muscles $(n=6) 3 \mathrm{~d}$ after partial denervation (Fig. 1). Most ( $95 \%)$ of the 100 bridges observed in these muscles had formed between a denervated and an innervated endplate. In these mus-
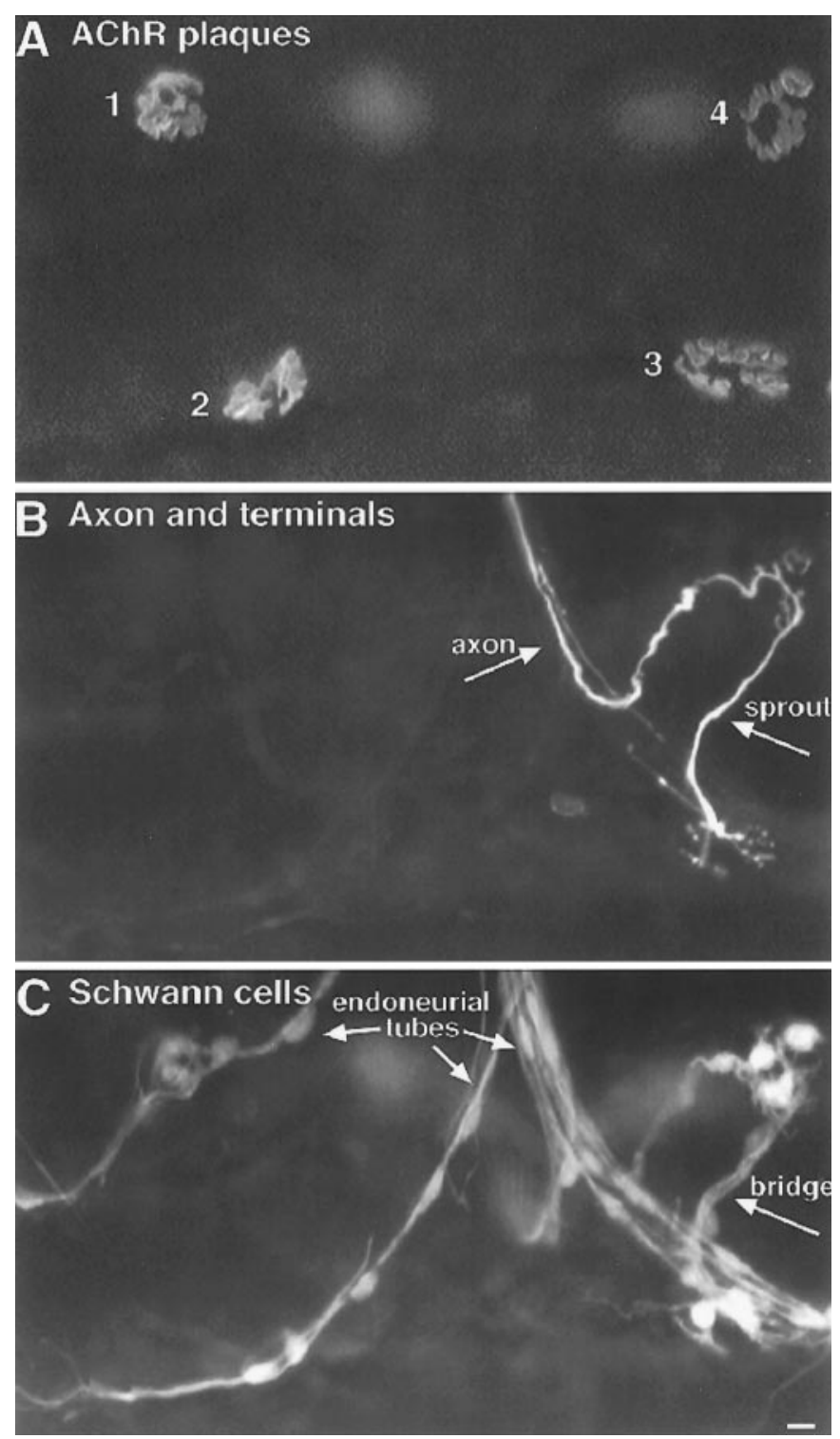

Figure 1. TSC processes extended from denervated endplates preferentially bridge with innervated endplates. Image of a triple-labeled rat soleus muscle $3 \mathrm{~d}$ after partial denervation. $A$, Labeling of acetylcholine receptors with $C y 5$-conjugated $\alpha$-bungarotoxin. $B$, Labeling of axons and nerve terminals with antibodies to neurofilament and synaptic vesicle protein and a FITC-conjugated secondary antibody. $C$, Labeling of Schwann cells with anti-S100 antibody and a rhodamine-conjugated secondary antibody. There are four endplates in focus in this region of the muscle $(A$, numbers). Endplates 1 and 2 lack nerve contact and therefore were denervated by the partial denervation and have not become reinnervated. Endplate 3 is innervated by a sprout growing from endplate 4, showing that endplate 3 was denervated but has become reinnervated. Endplate 4 is innervated by an axon that was not damaged during the partial denervation. Examination of the SC labeling in $C$ shows that TSCs form a bridge between endplates 3 and 4. SC labeling is also associated with the endoneurial tubes, i.e., the SC wrappings of axons and of the pathways previously occupied by axons. SC processes are extended from the denervated endplates 1,2 , and 3, but only endplate 3 is linked to an adjacent endplate by these processes. The processes from endplates 1 and 2 extended parallel with the muscle fibers (oriented horizontally in this image), not toward each other. Note that the newly established nerve terminal at endplate 3 is extending sprouts that have partially grown up the endoneurial tube. Scale bar, $10 \mu \mathrm{m}$. 

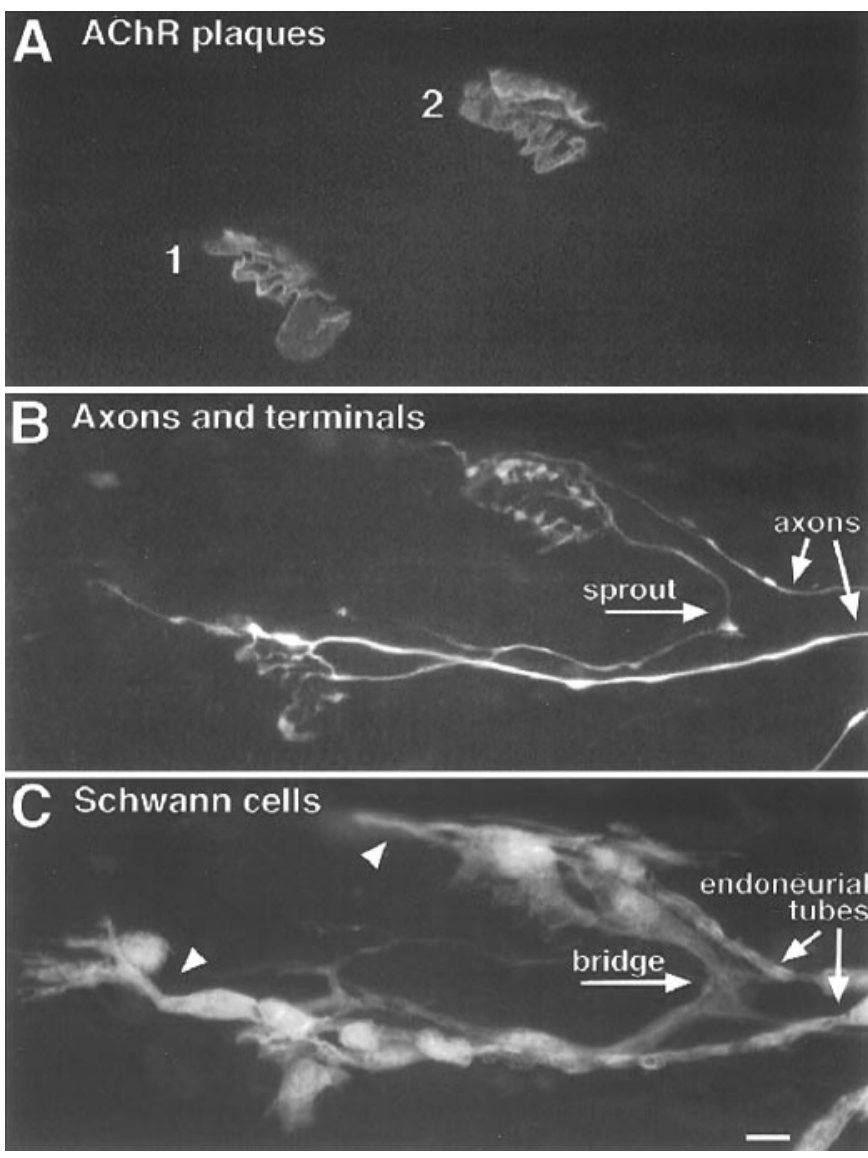

Figure 2. Bridges form during muscle reinnervation. Image of a TSC bridge linking two endplates during reinnervation $12 \mathrm{~d}$ after nerve crush. Labeling as in Figure 1. Although both endplates $(A, 1$ and 2$)$ have been reinnervated, TSC processes extended during the period of denervation ( $C$, arrowheads) have not yet completely retracted, and both nerve terminals still have processes (so-called "escaped fibers") extended onto these TSC processes. Note that the nerve sprout that connects the two endplates is associated with a TSC bridge. Axons are present in each of the endoneurial tubes leading to endplates 1 and 2. It is not possible to determine which direction the sprout grew across the bridge. Scale bar, $10 \mu \mathrm{m}$.

cles, $74 \%$ (1437 of 1931) of the endplates examined were denervated. Thus, despite the fact that approximately three of every four fibers were denervated, and TSC processes were extending from all denervated endplates, only $5 \%$ of the bridges were connecting denervated endplates. This suggests that SC processes from denervated endplates preferentially form (or maintain) bridges with innervated endplates. All such bridges were supporting the growth of terminal sprouts.

\section{The number of Schwann cell bridges rises during muscle reinnervation}

TSC bridges also form during the course of muscle reinnervation (Fig. 2; Son and Thompson, 1995a). If, as in the case of partial denervation, bridge formation or maintenance occurs preferentially with innervated synaptic sites, then the frequency of bridges should increase as the muscle becomes progressively reinnervated before TSC processes extended during denervation are withdrawn. To investigate this possibility, the incidence of bridges was compared in soleus muscles $12 \mathrm{~d}$ after crush of the muscle nerve (at which time, essentially all endplates were reinnervated) and in muscles $12 \mathrm{~d}$ after nerve resection (in which case no reinnervation had occurred). In the reinnervated muscles, $24 \pm 1 \%$ of the endplates were interconnected by a TSC bridge (Table 1, Fig. $3 A$ ). In contrast, only $6 \pm 2 \%$ of the endplates in the denervated muscles without reinnervation were linked by bridges $(p<$ 0.0008). As in the case of the partial denervations, this fourfold increase in bridge formation in the presence of innervated synaptic sites suggests that an innervation-dependent signal facilitates the formation or stabilization of bridges.

\section{Synaptic activity facilitates the formation of Schwann cell bridges}

Observations made during the course of muscle reinnervation suggested that the facilitation of bridge formation by innervation may require effective synaptic transmission. In addition to the data described above collected from muscles $12 \mathrm{~d}$ after nerve crush, observations were also made 7-8 d after nerve crush (Table 1, Fig. $3 A$ ). Although an average of $94 \%$ of the endplates had been contacted by regenerating axons at this time, only $11 \pm$ $2 \%$ of all the endplates were linked by a bridge. This frequency of bridges is significantly less than that $4-5 \mathrm{~d}$ later, at $12 \mathrm{~d}$ (Table 1 ; $p<0.001)$. Despite nerve contact of most endplates at $7-8 \mathrm{~d}$, reinnervation was clearly incomplete: terminals labeled by immunocytochemistry incompletely covered the old synaptic sites identified by labeling acetylcholine receptors (data not shown), and muscles failed to maintain tension after repetitive nerve stimulation (Fig. 3B). Because muscles stimulated directly did maintain tension, this latter observation suggests that synapses present in the muscle were weak. In contrast, muscles $12 \mathrm{~d}$ after nerve crush had terminals that had completely reoccupied the synaptic sites (data not shown), and muscle contractions followed repetitive stimulation of the muscle nerve much more faithfully (Fig. $3 B$ ). Taken together, these observations suggested that bridge frequency increases during muscle reinnervation as effective synaptic transmission returns.

To directly test the importance of synaptic activity in bridge formation, we examined the effect of paralysis. Soleus muscles of 10 -week-old rats were partially denervated and immediately treated with botulinum toxin (botox), a presynaptic neurotoxin that prevents release of synaptic vesicles (Pearce et al., 1997). When examined either 3 or 7 d later, bridge formation was inhibited in these muscles (Table 1, Fig. 4). Compared with partially denervated muscles that were treated only with the vehicle used for botox applications, there was a fivefold reduction in the frequency of bridges $(p<0.002)$. The reduction in bridge formation by botox cannot be explained by an effect on the growth of TSC processes from denervated endplates. The number and length of TSC processes in the muscles treated with botox for $7 \mathrm{~d}$ were not significantly different from muscles treated with vehicle (Table 2). Because most bridges in these muscles were associated with nerve sprouts (and all sprouts reinnervating endplates were associated with bridges), the reduction in bridges was mirrored by a reduction in endplates innervated by terminal sprouts. This observation also indicates that botox treatment did not obviously impair the ability of bridges that did form to support nerve growth.

Botox could decrease bridge frequency either by blocking the release of transmitter (or some other molecule) from the presynaptic nerve terminal or by preventing the activation of postsynaptic acetylcholine receptors. In an attempt to distinguish between these two possibilities, paralysis was achieved using the acetylcholine receptor antagonist btx. However, maintaining blockade with this toxin was much more difficult than with botox, probably because of systemic toxicity, the turnover of acetylcho- 
Table 1. Schwann cell bridge formation during denervation, reinnervation, and partial denervation

\begin{tabular}{|c|c|c|c|c|}
\hline \multirow[b]{2}{*}{ Experiment } & \multicolumn{2}{|c|}{ Number of endplates examined } & \multirow{2}{*}{$\begin{array}{l}\text { Percentage of } \\
\text { endplates } \mathrm{w} / \text { bridges* }\end{array}$} & \multirow{2}{*}{$\begin{array}{l}\text { Percentage of bridges } \\
\text { w/sprouts }\end{array}$} \\
\hline & Innervated & Denervated & & \\
\hline Reinnervation (7-8 d) & $291 \pm 27$ & $20 \pm 6$ & $11 \pm 2$ & 88 \\
\hline Reinnervation (12 d) & $358 \pm 35$ & $1 \pm 1$ & $24 \pm 1$ & 98 \\
\hline Full denervation $(12 \mathrm{~d})$ & 0 & $192 \pm 13$ & $6 \pm 2$ & 0 \\
\hline \multicolumn{5}{|c|}{ Partial denervation (PD) in 10 -wk-old rats } \\
\hline PD \& botox for $3 \mathrm{~d}$ & $94 \pm 32$ & $387 \pm 13$ & $2 \pm 1$ & 89 \\
\hline PD \& vehicle for $3 \mathrm{~d}$ & $165 \pm 67$ & $269 \pm 18$ & $10 \pm 1$ & 94 \\
\hline PD \& botox for $7 \mathrm{~d}$ & $77 \pm 22$ & $310 \pm 23$ & $6 \pm 1$ & 93 \\
\hline PD \& vehicle for $7 \mathrm{~d}$ & $86 \pm 17$ & $362 \pm 39$ & $30 \pm 3$ & 100 \\
\hline \multicolumn{5}{|c|}{ PD in 5-wk-old rats; muscles examined $3 \mathrm{~d}$ later } \\
\hline Btx initiated $48 \mathrm{hr}$ after PD & $199 \pm 101$ & $557 \pm 95$ & $9 \pm 3$ & 100 \\
\hline Vehicle initiated $48 \mathrm{hr}$ after PD & $155 \pm 27$ & $391 \pm 38$ & $21 \pm 1$ & 100 \\
\hline Botox initiated $44 \mathrm{hr}$ after PD & $124 \pm 17$ & $455 \pm 25$ & $14 \pm 2$ & 100 \\
\hline Vehicle initiated $44 \mathrm{hr}$ after PD & $143 \pm 28$ & $596 \pm 82$ & $25 \pm 2$ & 100 \\
\hline
\end{tabular}

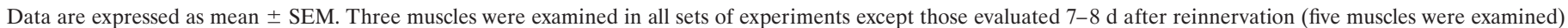
and muscles treated with botox $44 \mathrm{hr}$ after PD (four muscles were examined).

*Percentage of bridges is of all endplates (denervated and innervated) in reinnervation experiments and of innervated endplates in PD experiments.

line receptors (Fumagalli et al., 1990), and upregulation of transmitter release by nerve terminals unable to activate the postsynaptic cell (Plomp et al., 1992). The protocol used with botox was therefore modified for btx. Preliminary experiments suggested that a substantial increase in bridge formation occurred during the $24 \mathrm{hr}$ period between 48 and $72 \mathrm{hr}$ after partial denervation. Thus, btx was initially applied $48 \mathrm{hr}$ after partial denervation. A second application of btx $12 \mathrm{hr}$ after the initial dose was found to maintain a reasonably effective block for a period of $24 \mathrm{hr}$. At the conclusion of $24 \mathrm{hr}$ of such treatment in 5- to 6-week-old rats, there was a dramatic reduction in the ability of the btx-treated muscles to sustain tension during tetanic stimulation of the nerve at all frequencies tested $(20,50$, and $100 \mathrm{~Hz})$. Peak tensions were on average $8 \%(1.4 / 17.1 \mathrm{gm})$ of those in vehicle-treated muscles. Furthermore, vehicle-treated muscles maintained tension for the entirety of a $1500 \mathrm{msec}$ duration stimulus train, whereas the tension in btx-treated muscles generally peaked in $100 \mathrm{msec}$ and fell to zero within $500 \mathrm{msec}$. Compared with the vehicle-treated muscles, there was a greater than twofold reduction in the frequency of bridges in the btx-treated muscles $(p<0.01)$ (Fig. 5, Table 1). In fact, the percentage of bridges found in muscles $3 \mathrm{~d}$ after partial denervation after btx treatment for the final $24 \mathrm{hr}$ was not significantly different $(p<0.13)$ from that present in a series of muscles examined $2 \mathrm{~d}$ after partial denervation (Table 1 ), i.e., at the beginning of btx blockade. The btx-induced reduction in bridges did not occur as a consequence of reduced TSC growth. The length of processes and the number of processes extended from denervated endplates were similar to those in vehicletreated controls (Table 2). As with the botox-treated muscles, TSC bridges that did form in btx-treated muscles were associated with terminal sprouts (Table 1), suggesting that paralysis induced by btx does not interfere with the ability of bridges to support nerve growth.

To enable comparison of the potency of btx and botox in inhibiting bridge formation, we applied botox to 5- to 6-week-old rat muscles using a protocol similar to that used in the case of btx. Preliminary experiments showed that, whereas btx-treated muscles were almost completely blocked $1 \mathrm{hr}$ after application of the toxin, complete block with botox was not evident until $5 \mathrm{hr}$ after application (data not shown). Thus, to compare bridge formation over an equivalent period of blockade in the two cases, botox was applied $4 \mathrm{hr}$ earlier (at $44 \mathrm{hr}$ after partial denervation) than in the experiments described above. The frequency of bridge formation at $72 \mathrm{hr}$ in the presence of botox was not significantly different $(p<0.15)$ from that in the presence of btx (Table 1$)$, suggesting that presynaptic and postsynaptic block led to a similar inhibition of bridge formation.

\section{DISCUSSION}

Terminal Schwann cells appear to play a crucial role in the reinnervation of denervated endplates by sprouts from adjoining nerve terminals. TSCs extend processes after denervation of their synaptic site, and these processes promote the reinnervation of this site by growing into contact with a nearby nerve terminal, inducing the growth of a sprout from this nerve terminal, and then guiding this sprout to the denervated synaptic site (Son and Thompson, 1995b). This type of growth by TSCs appears to be necessary for terminal sprouting because such sprouting is absent from neonatal muscles in which the TSCs at denervated synaptic sites die (Lubischer and Thompson, 1999). How TSC processes manage to contact innervated synaptic sites is unclear. Although there were some suggestions in a previous study of instances of directed growth of TSC processes toward innervated synaptic sites (Son and Thompson, 1995b), assessment of the extent of such directed growth is difficult given the complex geometrical relationship among the synaptic sites in the bands of endplates extending across muscles. The initial models for TSC involvement in reinnervation by terminal sprouts therefore proposed that bridges between denervated and innervated sites were random events. The experiments presented here suggest that the process is far more interesting.

Clearly, TSC bridge formation occurs at a much higher frequency in the presence of nearby nerve terminals. This is evident both from observations in partially denervated muscles and in muscles being reinnervated after complete denervation. In the first case, bridges are more prevalent between innervated and denervated sites, despite the presence of extensive TSC growth and a partial denervation so severe that there were three times as many denervated as innervated sites. In the second case, TSCs extended extensive processes but seldom linked adjacent, dener- 

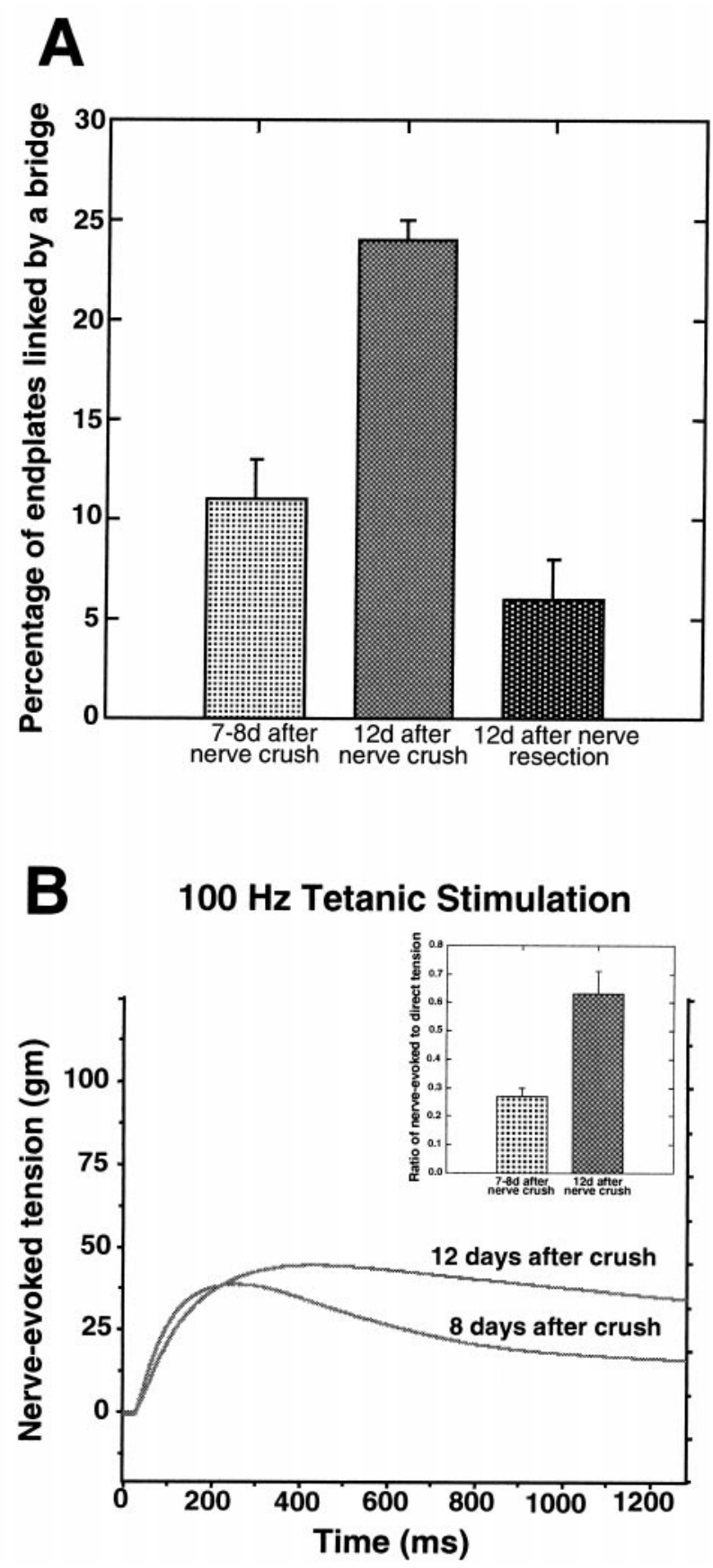

Figure 3. Bridge formation increases during reinnervation as synapses strengthen. $A$, Comparison of the percentage of endplates linked by a bridge 7-8 d after nerve crush, $12 \mathrm{~d}$ after nerve crush, and $12 \mathrm{~d}$ after nerve resection. More bridges are found $12 \mathrm{~d}$ after nerve crush than at 7-8 $\mathrm{d}$ (Student's $t$ test; $p<0.001$ ). In addition, more bridges are found in muscles undergoing reinnervation than in muscles that remain denervated by nerve resection $(p<0.001)$. B, Representative tension curves produced by two muscles in response to $100 \mathrm{~Hz}$ tetanic nerve stimulation 8 and $12 \mathrm{~d}$ after nerve crush. The insert summarizes results from the reinnervation experiments by showing the fraction of the nerve-evoked tension compared to the direct tension at $1300 \mathrm{msec}$ into a $100 \mathrm{~Hz}$ train of stimuli. This fraction is much smaller $7-8 \mathrm{~d}$ than $12 \mathrm{~d}$ after nerve crush, consistent with less effective synaptic transmission at the earlier time points. Values are expressed as mean \pm SEM.

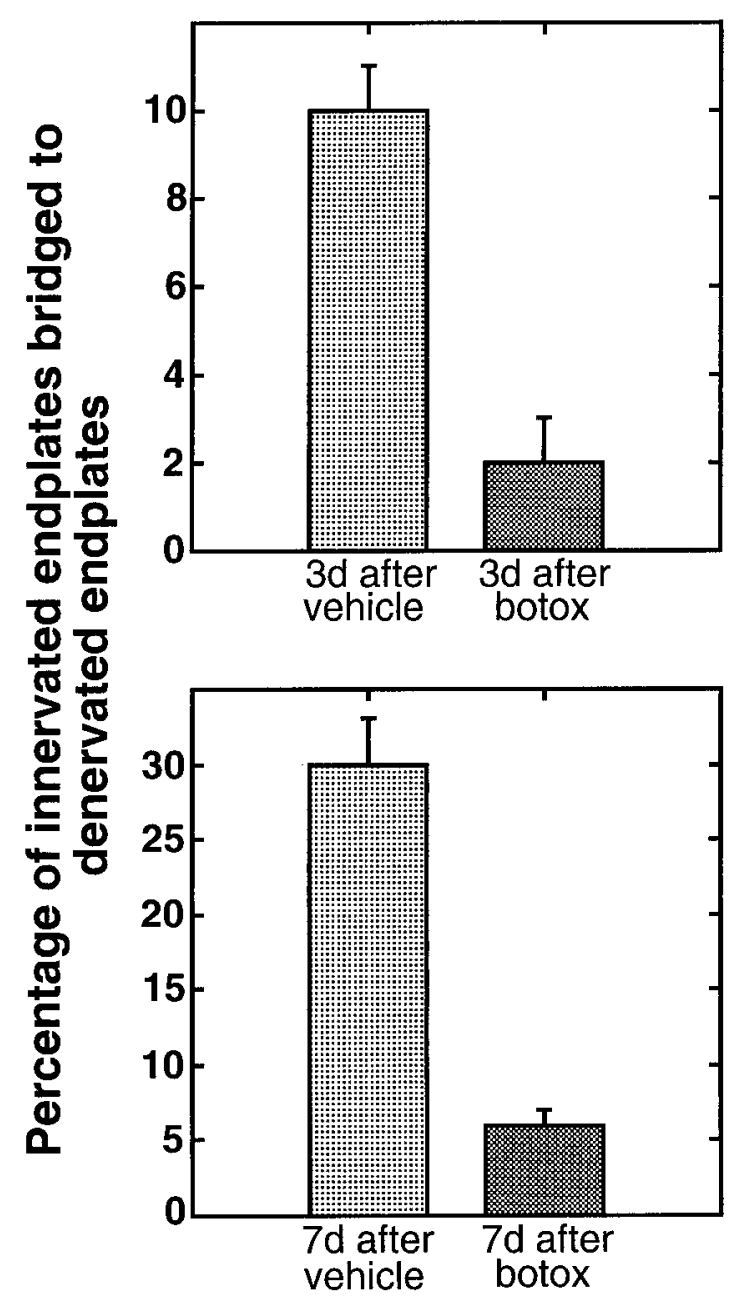

Figure 4. Presynaptic block reduces TSC bridge formation. Comparison of the extent of bridge formation in partially denervated muscles of 10 -week-old rats treated with botulinum toxin (botox) with those treated with vehicle. Botox was applied immediately after partial denervation. Comparisons were made at 3 and $7 \mathrm{~d}$ later. Fewer bridges are found in botox-treated muscles at both time points [Student's $t$ test; $p<0.002(3 \mathrm{~d})$; $p<0.001(7 \mathrm{~d})]$.

\section{Table 2. Schwann cell process growth after partial denervation} and paralysis

\begin{tabular}{lll} 
Experiment & $\begin{array}{l}\text { Average number of TSC } \\
\text { processes per endplate }\end{array}$ & $\begin{array}{l}\text { Average length of TSC } \\
\text { processes }(\mu \mathrm{m})\end{array}$ \\
\hline $\begin{array}{l}\text { Presynaptic block } \\
\text { with botox (7 d) }\end{array}$ & $7 \pm 1$ & $53 \pm 2 \mu \mathrm{m}$ \\
$\begin{array}{l}\text { Vehicle for botox } \\
\quad(7 \mathrm{~d})\end{array}$ & $8 \pm 1^{*}$ & $57 \pm 2 \mu \mathrm{m}^{* *}$ \\
Postsynaptic block & & \\
$\quad$ with btx & $5.8 \pm 0.3$ & $37 \pm 1 \mu \mathrm{m}$ \\
Vehicle for btx & $6.0 \pm 0.4^{* * *}$ & $36 \pm 1 \mu \mathrm{m}^{* * * *}$
\end{tabular}

$\overline{\text { Data are expressed as mean } \pm \text { SEM. Values are not significantly different between }}$ paralyzed and vehicle-treated muscles.

${ }^{*} p<0.2 ;{ }^{* *} p<0.1 ;{ }^{* * *} p<0.34 ;{ }^{* * * *} p<0.27$.

vated endplates until reinnervation of the muscle began, and nerve terminals were present on fibers adjacent to denervated (or as yet poorly reinnervated) fibers. Interestingly, bridges form and are maintained during reinnervation even as the TSC processes 


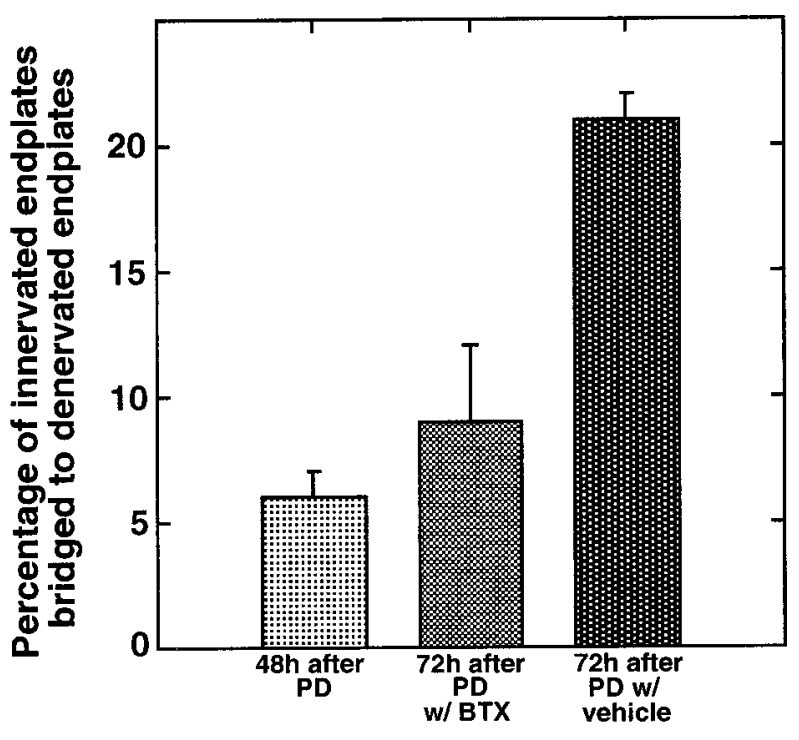

Figure 5. Postsynaptic block reduces TSC bridge formation. The extent of bridge formation in partially denervated, 5-week-old rat soleus muscles treated with $\alpha$-bungarotoxin (btx) or with vehicle. Btx or vehicle was applied to the muscle $48 \mathrm{hr}$ after partial denervation, and bridges were examined $24 \mathrm{hr}$ later. Fewer bridges are found in btx-treated muscles compared to those treated with vehicle $(p<0.01)$. In fact, the number of bridges seen in the btx-treated muscles is not significantly different from the number present in muscles partially denervated for $48 \mathrm{hr}(p<0.13)$, i.e., the number present at the time of btx application. This suggests that there is essentially no bridge formation in the presence of btx-induced paralysis.

extended during denervation begin to be withdrawn (Reynolds and Woolf, 1992). How then do transmitting nerve terminals promote bridge formation? One possibility is that these bridges form as a consequence of a chemotactic influence originating from innervated sites on the processes extended by TSCs at denervated sites. Chemotactic guidance of nerve sprouts has been suggested in the case of muscle fibers regenerating after fiber ablation (Van Mier and Lichtman, 1994). However, in our experiments it is equally plausible that there is some kind of stabilization of randomly formed bridges when these bridges come into contact with nerve terminals, perhaps even as a consequence of the growth of nerve sprouts onto the TSC bridge. It is also possible that both types of events are occurring. At present we do not have the means to distinguish between these possibilities.

Our observation that bridge frequency increased as reinnervated synapses became more effective suggested that bridge formation is facilitated by synaptic transmission before the gradual withdrawal of TSC processes that occurs after reinnervation. Evidence in support of this hypothesis was generated by showing that presynaptic block with botulinum toxin or postsynaptic block with $\alpha$-bungarotoxin reduced the frequency of bridge formation. Thus, our experiments suggest that some factor produced by the postsynaptic muscle fiber as a consequence of its synaptic activation facilitates bridge formation. Candidate trophic factors, chemotactic agents, and adhesion molecules exist. Examples include glial growth factor (Cohen et al., 1992; Jo et al., 1995; Moscoso et al., 1995; Mahanthappa et al., 1996; Carroll et al., 1997; Rosenbaum et al., 1997; Eilam et al., 1998), NT-4 (Funakoshi et al., 1995), and the adhesion molecules, L1 and $N$-cadherin (Nieke and Schachner, 1985; Seilheimer and Schachner, 1988; Letourneau et al., 1991; Cifuentes-Diaz et al., 1994; Martini, 1994; Itoh et al., 1995, 1997). Such a mechanism would likely increase the efficiency of the sprouting process, ensuring that nerve growth is directed to denervated synaptic sites, sites where reinnervation is favored.

Our experiments suggest that innervated, active muscle fibers produce a signal important for nerve sprouting. Much of the previous work on neuromuscular sprouting has been interpreted as indicating the opposite: that denervated, inactive muscle fibers release signals that promote and attract nerve growth. For example, Brown and Holland (1979) showed that nerve terminal sprouts were suppressed in partially denervated muscles in which the muscles were activated by direct stimulation, but not by stimulation of the remaining motor axons. Thus, activation of denervated, but not innervated fibers appeared to reduce sprouting. Furthermore, paralysis of normally innervated muscles achieved by blocking transmitter release, acetylcholine receptors, or nerve conduction (Duchen and Strich, 1968; Brown and Ironton, 1977; Holland and Brown, 1980) induced sprouting.

We believe that the contradictions here can be resolved by the recognition that there are two types of terminal sprouting, those sprouts that form new synapses on denervated junctions by growing along TSC bridges, and short, transient sprouts associated with short extension of processes by TSCs present at innervated endplates (Son and Thompson, 1995b). By $7 \mathrm{~d}$ after partial denervation, TSC processes extending from innervated endplates, and the terminal sprouts growing along them, have largely retracted (F. M. Love, unpublished observation). In contrast, growth of TSC processes from denervated endplates is extensive, and the number of TSC bridges increases during this time. Support for this dichotomy in sprouting comes from the experiments of Betz et al. (1979), who found that nerve sprouts in partially paralyzed muscles were approximately half as long as those in partially denervated muscles and seldom made synaptic contacts. We believe that, although the short, transient sprouts may be influenced by factors from denervated, or inactive muscles, the TSC bridges and the sprouts that grow along them are influenced by signals arising from active nerve terminals. Thus, active nerve terminals play a crucial role in the reinnervation of denervated endplates by terminal sprouts. Last, we note that our view of sprouting does not exclude a role for denervated fibers in this process. Indeed, the growth of TSCs from endplates on these fibers appears to be critically important in the sprouting process.

\section{REFERENCES}

Betz W, Caldwell J, Ribchester R (1979) Sprouting of active nerve terminals in partially inactive muscles of the rat. J Physiol (Lond) 303:281-297.

Brown MC, Holland R (1979) A central role for denervated tissues in causing nerve sprouting. Nature 282:724-726.

Brown MC, Ironton R (1977) Motor neuron sprouting induced by prolonged tetrodotoxin block of nerve action potentials. Nature 265:459-461.

Brown MC, Holland RL, Hopkins WG (1981) Motor nerve sprouting. Annu Rev Neurosci 4:17-42.

Carroll SL, Miller ML, Frohnert PW, Kim SS, Corbett JA (1997) Expression of neuregulins and their putative receptors, erbB2 and erbB3, is induced during Wallerian degeneration. J Neurosci 17:1642-1659.

Cifuentes-Diaz C, Nicolet M, Goudou D, Rieger F, Mege RM (1994) $N$-cadherin expression in developing, adult and denervated chicken neuromuscular system: accumulations at both the neuromuscular junction and the node of Ranvier. Development 120:1-11.

Cohen JA, Yachnis AT, Arai M, Davis JG, Scherer SS (1992) Expression of the neu proto-oncogene by cells during peripheral nerve development and Wallerian degeneration. J Neurosci Res 31:622-634.

Duchen LW, Strich SJ (1968) The effects of botulinum toxin on the 
pattern of innervation of skeletal muscle in the mouse. Q J Exp Physiol 53:84-89.

Eilam R, Pinkas-Kramarski R, Ratzkin BJ, Segal M, Yarden Y (1998) Activity-dependent regulation of Neu differentiation factor/neuregulin expression in rat brain. Proc Natl Acad Sci USA 95:1888-1893.

Fumagalli G, Balbi S, Cangiano A, Lømo T (1990) Regulation of turnover and number of acetylcholine receptors at neuromuscular junctions. Neuron 4:563-569.

Funakoshi H, Belluardo N, Arenas E, Yamamoto Y, Casabona A, Persson H, Ibanez C (1995) Muscle-derived neurotropin-4 as an activitydependent trophic signal for adult motor neurons. Science 268:1495-1499.

Holland RL, Brown MC (1980) Postsynaptic transmission block can cause terminal sprouting of a motor nerve. Science 207:649-651.

Itoh K, Stevens B, Schachner M, Fields RD (1995) Regulated expression of the neural cell adhesion molecule L1 by specific patterns of neural impulses. Science 270:1369-1372.

Itoh K, Ozaki M, Stevens B, Fields RD (1997) Activity-dependent regulation of $N$-cadherin in DRG neurons: differential regulation of $N$-cadherin, NCAM, and L1 by distinct patterns of action potentials. J Neurobiol 33:735-748.

Jo SA, Zhu X, Marchionni MA, Burden SJ (1995) Neuregulins are concentrated at nerve-muscle synapses and activate ACh-receptor gene expression. Nature 373:158-161.

Letourneau PC, Roche FK, Shattuck TA, Lemmon V, Takeichi M (1991) Interactions of Schwann cells with neurites and with other Schwann cells involve the calcium-dependent adhesion molecule, $N$-cadherin. J Neurobiol 22:707-720.

Liley AW (1956) An investigation of spontaneous activity at the neuromuscular junction of the rat. J Physiol (Lond) 132:650-666.

Love FM, Thompson WJ (1998a) Motor axon terminals promote the directed growth and/or stabilization of Schwann cell processes bridging endplates following nerve injury. Soc Neurosci Abstr 23:1035.

Love FM, Thompson WJ (1998b) Schwann cells proliferate at rat neuromuscular junctions during development and regeneration. J Neurosci 18:9376-9385.

Lubischer JL, Thompson WJ (1999) Neonatal partial denervation results in nodal, but not terminal sprouting and a decrease in efficacy of remaining neuromuscular junctions in rat soleus muscle. J Neurosci 19:8931-8944

Mahanthappa NK, Anton ES, Matthew WD (1996) Glial growth factor 2, a soluble neuregulin, directly increases Schwann cell motility and indirectly promotes neurite outgrowth. J Neurosci 16:4673-4683.
Martini R (1994) Expression and functional roles of neural cell surface molecules and extracellular matrix components during development and regeneration of peripheral nerves. J Neurocytol 23:1-28.

Moscoso LM, Chu GC, Gautam M, Noakes PG, Merlie JP, Sanes JR (1995) Synapse-associated expression of an acetylcholine receptorinducing protein, ARIA/heregulin, and its putative receptors, erbB2 and erbB3, in developing mammalian muscle. Dev Biol 172:158-169.

Nieke J, Schachner M (1985) Expression of the neural cell adhesion molecules L1 and NCAM and their common carbohydrate epitope L2/HNK-1 during development and after transection of the mouse sciatic nerve. Differentiation 30:141-151.

Pearce LB, First ER, MacCallum RD, Gupta A (1997) Pharmacologic characterization of botulinum toxin for basic science and medicine. Toxicon 35:1373-1412.

Plomp JJ, Van Kempen GT, Molenaar PC (1992) Adaptation of quantal content to decreased postsynaptic sensitivity at single endplates in $\alpha$-bungarotoxin-treated rats. J Physiol (Lond) 458:487-499.

Reynolds M, Woolf C (1992) Terminal Schwann cells elaborate extensive processes following denervation of the motor endplate. J Neurocytol 21:50-66.

Rosenbaum C, Karyala S, Marchionni MA, Kim HA, Krasnoselsky AL, Happel B, Isaacs I, Brackenbury R, Ratner N (1997) Schwann cells express NDF and SMDF/n-ARIA mRNAs, secrete neuregulin, and show constitutive activation of erbB3 receptors: evidence for a neuregulin autocrine loop. Exp Neurol 148:604-615.

Seilheimer B, Schachner M (1988) Studies of adhesion molecules mediating interactions between cells of peripheral nervous system indicate a major role for L1 in mediating sensory neuron growth on Schwann cells in culture. J Cell Biol 107:341-351.

Son Y-J, Thompson WJ (1995a) Schwann cell processes guide regeneration of peripheral axons. Neuron 14:125-132.

Son Y-J, Thompson WJ (1995b) Nerve sprouting in muscle is induced and guided by processes extended by Schwann cells. Neuron $14: 133-141$

Thompson WJ, Jansen J (1977) The extent of sprouting of remaining motor units in partly denervated immature and adult rat soleus muscle. Neuroscience 2:523-535.

Van Mier P, Lichtman JW (1994) Regenerating muscle fibers induce directional sprouting from nearby nerve terminals: studies in living mice. J Neurosci 14:5672-5686. 